\title{
CULTURA MULTIMIDIÁTICA E INTERSEÇÃO DOS CAMPOS ARTÍSTICOS
}

\author{
Vera Lúcia FOLLAIN DE FIGUEIREDO \\ Pontifícia Universidade Católica do Rio de Janeiro \\ verafollain@gmail.com
}

crescente interseção dos campos artísticos, criando zonas de indistinção entre territórios
tidos, em princípio, como distintos, vem pontuando, desde a segunda metade do século
passado, a reflexão teórica em torno das relações entre cinema, vídeo e artes plásticas. Já nos anos de 1970, momento em que a grande revolução tecnológica das chamadas novas mídias apenas se anunciava como promessa, Gene Youngblood, no livro intitulado Expanded Cinema, propunha, a partir do surgimento da televisão, do vídeo e do computador, uma outra maneira de pensar o cinema, que incluiria todas as formas de expressão constituídas pela imagem em movimento. Em sentido expandido, vídeo e televisão, assim como criações multimídias, poderiam ser consideradas cinema.

Como assinalou Arlindo Machado, a ênfase no termo «expandido» revela uma mudança de estratégia analítica: em lugar de pensar os meios individualmente, a atenção se dirige para as passagens que se operam entre a fotografia, o cinema, o vídeo e as mídias digitais (2007: 69). Com essa perspectiva, vários teóricos, como Peter Weibel (2003), Raymond Bellour (1997), Jeffrey Shaw (2003) passam a empregar a expressão «cinema expandido» ao fazer referência à produção fílmica contemporânea que, estendendo-se para além do espaço da tela, caracteriza-se por variados modos de projeção, difusão e recepção das imagens em movimento. Reforça-se, assim, a concepção do cinema como intermídia, que já estava presente no livro de Youngblood: diante, por exemplo, do filme realizado para ser exibido em exposições nas quais a imagem cinematográfica é exposta como uma obra de arte na sala de um museu, ou face a uma cineinstalação, o campo cinematográfico é repensado. Os critérios definidores de sua especificidade são revistos, dentre estes, o dispositivo instituído de apresentação dos filmes -isto é, a projeção em sala escura de imagens em movimento sobre uma tela de grande formato, diante de espectadores sentados por um certo tempo- o que, aliás, havia sido problematizado pelas vanguardas europeias ainda nas primeiras décadas do século XX.

Com os avanços da tecnologia digital, o fenômeno da «expansão» dos limites de cada campo artístico ganha ainda mais proeminência, falando-se de escultura expandida, de fotografia expandida, de vídeo expandido, de televisão expandida e também de documentário expandido e de literatura 
expandida. No que diz respeito às chamadas artes plásticas, Rosalind Krauss assinala que categorias como escultura e pintura foram esticadas e torcidas pela crítica americana do pós-guerra numa demonstração extraordinária de elasticidade que evidencia como o significado de um termo cultural pode ser ampliado a ponto de incluir quase tudo. Diz Krauss:

Nos últimos 10 anos coisas realmente surpreendentes têm recebido a denominação de escultura: corredores estreitos com monitores de TV ao fundo; grandes fotografias documentando caminhadas campestres; espelhos dispostos em ângulos inusitados em quartos comuns; linhas provisórias traçadas no deserto. Parece que nenhuma dessas tentativas, bastante heterogêneas, poderia reivindicar o direito de explicar a categoria escultura. Isto é, a não ser que o conceito dessa categoria possa se tornar infinitamente maleável (1984: 87).

Para a historiadora de arte, a categoria escultura, bem como qualquer outro tipo de convenção, tem sua própria lógica interna, seu conjunto de regras, as quais, ainda que possam ser aplicadas a uma variedade de situações, não estariam em si próprias abertas a uma modificação extensa, ou seja, não seriam infinitamente maleáveis. Partindo desse pressuposto, Rosalind Krauss pergunta, então, se a categoria escultura, ao ser forçada a abranger campo tão heterogêneo, não correria o perigo de entrar em colapso. Conclui, entretanto, que tal preocupação não se justificaria no pós-modernismo, pois tratase de um momento no qual a práxis não seria definida em relação a um determinado meio de expressão, como a escultura ou a pintura. Seria definida em relação a operações lógicas dentro de um conjunto de termos culturais para o qual vários meios - fotografia, livros, quadros, espelhos ou escultura propriamente dita - podem ser usados: «o campo estabelece tanto um conjunto ampliado, porém finito, de posições relacionadas para determinado artista ocupar e explorar, como uma organização de trabalho que não é ditada pelas condições de determinado meio de expressão» (1984: 88).

Como sabemos, embora tenham se tornado mais comuns com o aprimoramento das tecnologias eletrônicas e digitais, os deslocamentos e expansões que abalam as especificidades de cada meio de expressão, constituindo uma questão central das artes contemporâneas, já se faziam presentes, pelo menos desde as colagens cubistas e dos readymades de Duchamp. A literatura também não ficou imune aos contínuos entrecruzamentos entre diferentes áreas da produção cultural, como atestam, mais recentemente, os transbordamentos da escritura para além dos limites da página nos videotextos. No entanto, esta questão não tem mobilizado, tanto quanto era de se esperar, os estudiosos da literatura: são os teóricos das áreas das Artes Plásticas, da História Cultural e da Comunicação que têm apresentado uma reflexão mais sistemática sobre as distensões da escrita e as interseções da literatura com os demais campos artísticos.

No Brasil, a convergência entre a literatura e as mídias digitais tem sido abordada frequentemente sob o signo do temor apocalíptico do fim do livro ou da euforia tecnológica face aos novos suportes eletrônicos dos textos, acompanhada de um certo deslumbramento com o potencial de divulgação das redes e com as novidades das edições digitais lançadas pelo mercado editorial. Algumas vezes, emprega-se a expressão «literatura expandida» para designar textos compostos pela montagem de citações de obras alheias, mesmo que esses textos sejam publicados em livros impressos, de forma convencional, ou seja, a noção de literatura expandida confunde-se com a de remixagem. O uso 
indiscriminado do termo «literatura expandida» acaba por colocar em segundo plano a reflexão, que o próprio termo suscita, sobre o destino daquilo que a modernidade convencionou chamar de literatura. Deixam-se de lado algumas perguntas importantes, como por exemplo: considerando, como lembra Krauss, que os campos artísticos se constituem historicamente, pode-se afirmar que, no contexto hipermidiático, uma nova lógica regerá o campo da literatura? A partir daí, o termo literatura passará a abranger uma produção cujo principal meio de expressão não é necessariamente a palavra escrita?

A dissertação de mestrado em Artes Visuais, intitulada Literatura Expandida: arquivo e citação na obra de Dominique Gonzalez-Foerster, de Ana Pato, publicada em 2012, caminha nessa direção. A autora identifica na prática da artista plástica francesa o surgimento de uma forma de literatura expandida, que constituiria um caminho possível para a criação literária em meio a um mundo saturado de textos e imagens. As citações e apropriações de textos de outros artistas por Dominique GonzalezFoerster decorreriam da opção por uma lógica arquivista em consonância com a ideia do mundo como biblioteca — segundo o pensamento de Jorge Luis Borges - e com as mudanças na concepção de acervo trazidas pela tecnologia digital: este teria ganhado mais dinamismo no ambiente virtual, já que o público pode reagrupar textos ou fragmentos, realizando, a partir deles, um trabalho de reinterpretação e de criação.

Transitando entre o cinema, o vídeo e a instalação, a produção artística de Gonzalez-Foerster constrói-se através de citações de obras de cineastas, escritores, arquitetos e músicos, colocando em xeque o modelo convencional de autoria. Tal procedimento, segundo Ana Pato, transpõe para as artes visuais o método e o pensamento de autores contemporâneos, como Enrique Vila-Matas e J. C. Ballard, prenunciando um novo tipo de escrita e de literatura, que se expande para o espaço expositivo e se hibridiza com as artes visuais a exemplo do cinema experimental que, reclassificado como arte contemporânea, é exibido em galerias de arte. Ana Pato reconhece nesse processo a possibilidade de uma nova forma de literatura não mais circunscrita à palavra ou exclusivamente à comunicação linguística, mas pluridimensional: « um romance pode ser preenchido com personagens e lugares, descrições e diálogos, mas também com obras de arte» (Pato, 2012: 70), diz Dominique GonzalezFoerster, acrescentando:

Sempre quis escrever, mas não consegui. Para mim, a forma de escrever de Vila-Matas é muito clara. Entendo como ele combina a leitura, o déplacement, o encontro. Sinto-me gêmea de sua forma de construir o texto e da ideia de que tudo é material, cada encontro, cada leitura. E de que, no final, é tudo um grande trabalho de edição, de montagem (Pato, 2012: 70).

Seguindo uma tendência semelhante, trabalhos como Delírio de Damasco, da escritora e artista plástica Verônica Stigger, tanto a intervenção na Mostra SESC de Artes, em São Paulo, em 2010, quanto o livro derivado da exposição, confundem os contornos entre literatura e artes visuais. A exposição exibia placas de madeira, coladas em tapumes de uma construção no centro da cidade, com frases ouvidas na rua, como as seguintes: «Fome é meu estado natural»; «Isso é o que ela sente ou o que sente o coração dela?»; «Não pode. Por que não pode? Porque não pode». No livro, as frases são exibidas uma a uma em cada página. Declara a autora: 
Cultura multimidiática e interseção dos campos artísticos

Talvez tenha sido mais com os artistas plásticos do que com os escritores que aprendi a tomar gosto pela experimentação. Daí, eu trazer constantemente para o terreno da literatura procedimentos caros às artes visuais. Daí também minha preocupação com a forma que o livro terá. Para mim, a forma gráfica do livro é indissociável do texto. Enquanto escrevo, já vou pensando na forma que o livro deve assumir (2014).

Minha Novela, livro de Verônica publicado em 2013, foi apresentado originalmente em formato de vídeo, como parte de uma instalação, na mostra realizada na Embaixada do Brasil em Bruxelas, entre dezembro de 2012 e fevereiro de 2013. Na tela escura, o texto narrativo é exibido frase por frase, isto é, é expõe-se uma frase de cada vez, como se a obra fosse constituída pela sequência de manchetes jornalísticas sobre reviravoltas na vida de personagens de folhetins: «Ivanor troca Amélia pela batina». «Rosalva busca paz na igreja e se apaixona por Ivanor». «Com medo de ser preso, Juvenal se atira de um viaduto».

Também os murais do Paginário, de Leonardo Villaforte, compostos de páginas de vários livros, privilegiando a montagem em detrimento da escrita original, acabam por aproximar a prática de leitura e o movimento de livre circulação dos visitantes em espaço expositivo, o que evidentemente põe em discussão não só o conceito de escrita, a noção de autoria, como também a relação que tradicionalmente se estabeleceu entre o leitor e o suporte do livro. Sob o nome de Paginário, Leonardo realiza, desde 2013, instalações urbanas, em diferentes pontos do Rio de Janeiro, que consistem na colagem, em muros, de cópias de páginas de livros escolhidas por amigos do artista: as passagens preferidas de cada página são destacadas com marca-textos coloridos.

Já em O livro depois do livro, de Giselle Beiguelman - obra que reúne ensaios sobre literatura, leitura e internet, publicada no formato de website e de livro- destacam-se as transformações nas experiências de leitura que se abrem com a digitalização. Rejeitando a lógica da novidade iminente que, segundo a autora, «draga não só o passado, mas o próprio presente, arremessando-nos em um estranho estado de expectativa de um pós-futuro que nunca chega», Giselle descreve seu trabalho teórico da seguinte maneira:

Recusando esse tipo de abordagem (o da lógica da novidade iminente), interroga-se um contexto de leitura mediado por interfaces conectadas em Rede, discutindo projetos criativos que têm como denominador comum o fato de expandirem e redirecionarem o sentido objetivo do livro, permitindo pensar experiências de leitura pautadas pela hibridização das mídias e cibridização dos espaços (on-line e off-line) (2005: 10).

Diante de todas essas transformações nos modos de leitura e na concepção do que chamamos de livro, diante também das reflexões que tais mudanças vêm provocando em diversos campos do conhecimento, pode-se dizer que, no Brasil, na área acadêmica de Letras, os rumos da literatura, como campo artístico, têm sido pouco discutidos e, muitas vezes, a questão tem se diluido em meio ao debate sobre o futuro da cultura impressa. A literatura é, intrinsecamente, a arte do livro, como a definiram alguns pensadores? Se assim for, como delimitá-la a partir da mudança de suporte, isto é, do deslizamento dos textos para as telas? A literatura tal como a modernidade a concebeu seria ultrapassada com a hegemonia das escritas hipermidiáticas? Para Foucault, a literatura teria começado no dia em que o espaço da retórica foi substituído pelo que se poderia chamar o volume do livro, embora ela tenha sempre procurado transgredir esse espaço. Diz o filósofo que a literatura não deve 
ser compreendida nem como a linguagem do homem nem como a palavra de Deus, nem como a linguagem da natureza, nem como a linguagem do coração ou do silêncio, mas como a linguagem própria do livro: «uma linguagem transgressiva, mortal, repetitiva, reduplicada» (Machado, 2000: 154).

A questão da mudança de suporte não se constitui, desse modo, apenas num problema comercial, que afeta as editoras, como às vezes é tratada, já que, como observou Roger Chartier, os suportes materiais que permitem a leitura, a audição ou a visão dos textos participam profundamente da construção de seus significados (1992: 91):

\footnotetext{
Se os textos se emancipam das formas que os acompanham desde os primeiros séculos da era cristã —desde o códex, o livro composto por cadernos, do qual derivam todos os objetos impressos que nos são familiares - são, de fato, todas as tecnologias intelectuais, todas as operações em curso na produção de significações que se encontrarão modificadas (1999: 91).
}

Na era da tecnologia digital, filmes, fotografias, textos, músicas, traduzidos em dados numéricos, inserem-se numa rede não hierárquica de circulação. Torna-se importante lembrar, então, que, face a essa contínua torrente de transformação intertextual, de textos gerando outros textos em um processo incessante de reciclagem, textos literários vêm cada vez mais assumindo seu lugar como intermídia, para usar a expressão de Youngblood, servindo de prototexto no campo da produção cinematográfica, televisiva e digital. Como, na década de 1980, Umberto Eco destacava, no lugar do choque e da frustração de expectativas, ganha terreno, na era eletrônica, uma estética da repetição que vem minando o critério da originalidade característico da arte moderna. Identificada com os produtos veiculados pelos meios de comunicação de massa, essa estética da serialidade implica a ideia de infinitude do texto, cuja variabilidade se converteria em prazer estético (1985: 110).

No que diz respeito a relação da literatura com o audiovisual, a visibilidade da obra literária, como assinalado em Narrativas migrantes: literatura, roteiro e cinema (2010), foi se tornando, ao longo da segunda metade do século XX, cada vez mais tributária do fato de ter sido tomada como textobase para um filme (2010:44). O texto literário, visto por esse ângulo, passa a ocupar o lugar do argumento, do texto realizado para dar origem a um filme e que será lido a partir da mediação do espetáculo fílmico: chega-se à literatura por intermédio de sua versão audiovisual; esta ganha o status de obra final. Esse movimento não se restringe somente ao caso de reedição de obras que foram filmadas, colocando-se, na capa, fotos do filme, como tática de sedução para a compra do livro, mas dá lugar a uma série de outras estratégias que visam diluir as fronteiras entre as duas esferas de produção.

Dentre estas estratégias, está a recente utilização, pelas editoras, dos meios audiovisuais para divulgar livros. Pequenos filmes, de cerca de dois minutos, exibidos na internet, em sites, blogs de editoras e até no cinema, são usados como trailers de livros: no cinema, procura-se exibi-los antes de filmes que tenham alguma afinidade com a obra. O book trailer serve de chamariz para o texto, substituindo resenha e publicidade escritas nos moldes tradicionais, como se as palavras impressas fossem insuficientes para atrair leitores, que necessitariam de estímulos audiovisuais. Em diferentes 
formatos, de acordo com o tipo de livro que apresentam, os book trailers podem mostrar, por exemplo, cenas do autor lendo trechos selecionados, intercaladas com imagens de arquivo, como costuma acontecer com livros de historiografia. Outras vezes, ouve-se a poesia de um escritor consagrado na voz de um poeta com maior visibilidade midiática, de um ator ou cantor, enquanto imagens alusivas à obra ou à vida do autor do texto recitado são exibidas. Quando se trata de livros de ficção, o trailer busca sintetizar visualmente o enredo dessas narrativas: quase sempre conta com trilha sonora e é estrelado por atores, aproximando-se dos trailers de filmes. Há, no entanto, exceções, como o caso do romance Leite derramado (2009), de Chico Buarque de Hollanda: neste book trailer, por cinco minutos, o autor, em primeiro plano, lê algumas páginas do livro — a câmera só se desloca da imagem do escritor, cuja fama, no Brasil, se deve à sua carreira de cantor e compositor, para aproximar-se das páginas que estão sendo lidas, voltando em seguida para o autor.

O propósito de atrair o leitor/espectador pelo entrecruzamento do campo literário e do audiovisual, nos dias de hoje, evidentemente não se esgota nos book trailers. O mercado editorial tem investido também na publicação de roteiros e de relatos das etapas de elaboração de obras cinematográficas concluídas, além de obras híbridas nas quais se reúne material variado como fotos, entrevistas, depoimentos, críticas e, às vezes, o próprio roteiro. Tais mudanças no status do roteiro, devidas a iniciativas do mercado editorial, nos levaram a indagar, no livro mencionado - Narrativas migrantes - se poderíamos estender o termo literatura expandida a ponto de abrigar também os roteiros, já que estes são textos que se situam num entrelugar entre a literatura e o audiovisual e que, de certo modo, ultrapassam as fronteiras da comunicação verbal e do suporte impresso. A ampliação da publicação dos roteiros tem, inclusive, fortalecido a ideia, defendida por alguns profissionais do cinema, de que constituem um novo gênero narrativo, capaz de despertar o interesse do leitor comum, não especializado. Para o cineasta Sylvio Back, por exemplo, «o espectador adora virar "leitor de um filme", da linguagem e carpintaria do roteiro, como se ali encontrasse algum mistério revelado no que viu ou no que verá na tela, o que transforma, sim, o roteiro de cinema num gênero» (2009).

Se o espectador adora virar «leitor de filmes», como afirmou Sylvio Back, pode-se dizer também que o leitor cada vez mais vai se tornando «espectador de livros». Isto porque, buscando fazer uma literatura para ser lida como um filme, mais até do que para ser filmada, escritores utilizam tópicos da cultura audiovisual como mediação entre o texto e o leitor, evocando o mundo das imagens técnicas como forma de estabelecer uma ponte que favoreça o ir-e-vir entre o universo literário e o mundo das narrativas audiovisuais. Acrescente-se que, além do fato de, por vezes, o escritor já escrever visando facilitar futuras adaptações, aproximando o texto literário do formato dos roteiros, o espaço de tempo entre a publicação do livro e sua adaptação para o cinema reduziu-se significativamente. Essa aproximação entre os dois campos, que deixa marcas na escritura, é estimulada pelo mercado de bens culturais que, cada vez mais, trabalha com o reaproveitamento das matérias ficcionais disponíveis, distribuindo-as por plataformas diversas, o que fica evidente no caso das narrativas transmidiáticas, cujo processo de criação prevê, desde seu ponto de partida, a circulação das obras em suportes diferentes, como o livro e a tela do cinema ou da televisão. 
Como observou Rosalind Krauss, a expansão dos campos artísticos que caracteriza a contemporaneidade possui dois aspectos: «Um deles diz respeito à prática dos próprios artistas; o outro, à questão do meio de expressão. [...] Com relação à prática individual, é fácil perceber que muitos dos artistas em questão se viram ocupando, sucessivamente, diferentes lugares dentro do campo ampliado (1984: 90). Nesse contexto, a parceria entre escritores e cineastas, numa espécie de colaboração que transcende as fronteiras de cada campo ${ }^{1}$, tem sido frequente, o que tende a tornar obsoleta a própria noção de adaptação. Esta pressupõe a ideia de transposição de uma obra literária acabada, isto é, fechada em sua integridade, para o audiovisual. Pressupõe, portanto, sempre uma distância entre o trabalho do escritor e o do diretor. Distância que tem se tornado cada vez menor: daí a presença de escritores no set de filmagem, colaborando estreitamente com diretores e roteiristas, podendo ocorrer, inclusive, que os escritores atuem como roteiristas e até como atores de suas próprias obras. Cabe lembrar o caso de Lourenço Mutarelli, cuja carreira como escritor foi impulsionada a partir do momento em que $O$ Cheiro do Ralo chegou às telas de cinema e que atuou como ator na adaptação do romance realizada por Heitor Dhalia (2007). Mutarelli também participou como ator na adaptação, realizada por Paulo Machline (2011), de outra obra de sua autoria, Natimorto. Depois de O Cheiro do Ralo, publicado em 2002, dois de seus romances -Jesus Kid (2004) e Miguel e os demônios ou Nas delícias da desgraça (2009) - foram escritos sob encomenda para virar filmes.

Talvez por isso o romance Jesus Kid constitui-se numa crítica tão ácida à submissão dos escritores aos interesses da indústria cinematográfica e do mercado editorial. O livro nasceu de uma solicitação do diretor Heitor Dhalia, que necessitava de um roteiro para um filme de baixo orçamento. Mutarelli aceitou a encomenda, mas escreveu um romance para ser adaptado e não um roteiro. Neste romance, o personagem principal, chamado Eugênio, é um escritor de livros de entretenimento, que, necessitado de dinheiro para pagar contas, aceita a proposta de um produtor e de um diretor de cinema para escrever o roteiro de um filme. O contrato obriga Eugênio a escrever o roteiro num hotel, onde deverá ficar por três meses, sem poder sair, fazendo lembrar tanto a situação dos participantes de reality shows quanto de alguns projetos editoriais que implicam o deslocamento dos escritores para locais determinados pelos editores. O personagem do diretor no universo ficcional exige que o filme de Eugênio seja sobre um escritor, em crise criativa, que se lança em um projeto de escrever um roteiro para um filme. Por outro lado, o diretor também exige que o enredo tenha muita ação e inclua aventuras amorosas com mulheres e, como se vê na passagem abaixo, cita como exemplo do que deseja, o filme Adaptation (EUA, 2002), de Spike Jonze, com roteiro de Charles Kaufman:

-E toda história deve se passar no interior do hotel?

-Isso, desse hotel. Porque nós conhecemos o dono e ele vai deixar a gente rodar o filme aqui, na faixa. Isso nos economiza um montão de dinheiro.

—Eugênio, você viu Adaptation?

-Não, não vi.

—Porra Eugênio, que tipo de roteirista você quer ser se você não vai ao cinema?

\footnotetext{
${ }^{1}$ Cabe lembrar que, na década de 1960, o Nouveau Roman já pressupunha a colaboração transmidiática entre escritores e cineastas. Não é por acaso que Alain Robbe-Grillet e Marguerite Duras, ao lado de Alain Resnais, foram figuras emblemáticas daquele momento.
} 
—Eu não sei se quero ser roteirista.

$-[\ldots]$ E ele precisa inserir um pouco de favela, diga isso a ele.

-Favela?

-É, favela. Isso ajuda na captação.

- Mas como eu vou inserir favela em uma história que se passa, toda, dentro de um hotel?

- Porra, nós vamos ter que arrumar um DVD do Adaptation.

- Adaptation?

- Cara, nesse filme, o cara bota todos os ingredientes hollywoodianos numa história que fala de orquídeas. É mole?! (2004: 64).

Criando um enredo em abismo, que espelha de maneira caricatural a sua própria situação, Lourenço Mutarelli, em Jesus Kid, chama a atenção para uma série de questões que tensionam a escrita literária quando esta já nasce comprometida com a produção audiovisual. Destaca o fato de problemas financeiros característicos do cinema acabarem por impor restrições temáticas aos romances ou determinarem a escolha de temas que facilitam a captação de recursos, como os de cunho social, que, na versão «filme de favela», constituíram um gênero bastante explorado pelo que se convencionou chamar de Cinema de Retomada. Assinala, ainda, a preocupação com o sucesso de bilheteria, que induz à utilização de fórmulas garantidas de sucesso, como a mistura de ingredientes das narrativas de entretenimento com uma dose certa de metalinguagem. Como Heitor Dhalia observou no prefácio do livro, nada escapou à ironia de Mutarelli, voltada sobretudo para o cinema: o romance aponta de maneira cortante «as fraquezas, mesquinharias e ambições mal disfarçadas da atividade cinematográfica, que mescla arte e dinheiro. como nenhuma outra» (2004: 2).

$\mathrm{O}$ artifício utilizado por Mutarelli — a mistura de ingredientes das narrativas de entretenimento com uma certa dose de metalinguagem - já se tornou uma convenção narrativa dominante em nossa época, pouco afeita às radicalidades e às rupturas. Preserva-se o enredo, satisfazendo aquele leitor que busca se divertir com a intriga, mas também se oferece algo além da intriga: «uma dimensão metalinguística e reflexiva, reforçada por inúmeras citações, que permite a um outro tipo de leitor contemplar, de maneira distanciada as estratégias narrativas que criam o fascínio na primeira dimensão» (Figueiredo, 2010: 43). Por esse caminho, que, em certa medida, já havia sido trilhado, na literatura, pelo escritor argentino Manuel Puig, e, no cinema, dentre outros, por Pedro Almodóvar e Quentin Tarantino, coloca-se em primeiro plano as convenções e os esquematismos que evidenciam a opacidade do jogo narrativo, visando se contrapor à ilusão de transparência engendrada pelas imagens técnicas, que ocultam o trabalho da sua produção.

A interseção entre a obra literária e o campo do audiovisual, na atualidade, manifesta-se, assim, em diferentes níveis. Um outro caso bastante significativo é o diálogo constante travado entre o cineasta Beto Brant e a literatura de Marçal Aquino. Para citar apenas um exemplo mais recente, o diretor, que adaptou o livro Eu receberia as piores notícias dos seus lindos lábios (2005), de autoria de Aquino, para o cinema, produziu uma minissérie de televisão em quatro episódios, exibida em julho de 2009, partindo de um personagem secundário do romance: o psicanalista Benjamin Schianberg. O mesmo material deu origem a um filme longa metragem. A minissérie, realizada a convite da TV Cultura e do SESC TV, em coprodução com a Drama Filmes, acompanhou o início do relacionamento amoroso entre um ator e uma artista plástica, a partir da convivência no interior de um apartamento, 
durante três semanas. A proposta envolvia a instalação de câmeras no apartamento, como num reality show, com o diferencial de que os atores não estariam confinados. Na narrativa audiovisual, o personagem Schianberg, um psicanalista que reflete sobre o comportamento amoroso a partir do relacionamento de casais por ele observados, é representado pela voz de um narrador, que analisa a relação dos atores Gustavo Machado e Marina Previato. Segundo Beto Brant, não havia uma dramaturgia previamente escrita. Diz o diretor:

A gente criou uma regra: contaminar o menos possível. Saíssem quando quisessem, limpassem o apartamento. E eu me comunicava com e-mails, torpedos, que era uma forma de manter contato sem contaminar. E de brincar mesmo! Eu estava em outro apartamento, com joysticks, com oito câmeras, como se fosse um game mesmo, buscando enquadramento e olhares, flagrando detalhes que acrescentassem significados no filme. Eu era o próprio Schianberg! (2010).

Desse modo, o personagem de Eu receberia as piores notícias dos seus lindos lábios deu origem a uma outra narrativa que se realizou de forma aberta, incorporando os elementos do dia-a-dia dos atores às tramas sugeridas por um esboço de roteiro. Em certo sentido, podemos dizer que o romance de Aquino expandiu-se, dando origem a um filme e a uma minissérie que, por sua vez, dilui os contornos entre a ficção e o documentário. Beto Brant estabeleceu um diálogo com o modelo televisivo dos reality shows, tendo como mediação o personagem do livro. Encontra-se aí mais uma vez um exemplo do esforço empreendido pelos artistas no sentido de extrair potência inventiva de lugarescomuns temáticos e formais oriundos da cultura massiva, dobrando-se sobre ela.

Como a popularização dos meios eletrônicos coincide com a penetração do mercado em cada esfera da produção cultural, a literatura contemporânea tenta se equilibrar não só entre o texto e a imagem, mas também entre o campo da arte tal como instituído pela modernidade, com sua pressuposta autonomia, e o do mercado de bens simbólicos, com suas exigências de ordem econômica. Se a autonomia da arte, como afirmou Andreas Huyssen, foi mais um ideal a alcançar do que uma situação conquistada, havendo sempre o perigo de desestabilização das fronteiras entre alta e baixa cultura (1996: 32), a grande diferença do quadro atual para o do passado talvez esteja no deslizamento da narrativa de ficção de gosto popular, do suporte impresso do jornal, na forma de folhetim, para as telas.

Preocupado com o destino dos textos em meio à profusão de imagens técnicas, Vilém Flusser dedica um dos capítulos do livro A escrita - há futuro para a escrita? aos roteiros. Ao defini-los, o autor destaca o fato de serem textos que não se dirigem a editores e por meio destes aos leitores, mas aos produtores de cinema. Para ele, os roteiristas são pessoas que pisam em chão escorregadio, num plano inclinado que serve de ponte entre «o planalto da cultura escrita» e o «precipício da cultura das imagens técnicas», estando sempre a ponto de rolar nesse precipício (1987: 146). Segundo Flusser, de maneira semelhante aos equilibristas, os roteiristas tentam manter o equilíbrio entre texto e imagem por meio de uma acrobacia literária, mas não conseguem, porque o campo de gravidade das imagens os puxa. Diz o autor: «Se o roteiro fosse um número no circo público (os roteiristas se defrontariam com o público no coliseu da mídia), todos ouviriam falar de sua fama em todos os lugares. Ele preencheria o espaço da cultura escrita, que está se esgotando, como um grito estridente: "morituri te salutant”» (1987: 147). 
$\mathrm{Na}$ perspectiva do filósofo tcheco, os roteiros para produtos audiovisuais seriam um duplo engano: simulam que são textos quando são programas de imagens. Seriam o canto do cisne da literatura, a despedida melancólica da literatura:

\footnotetext{
Quem escreve roteiros rendeu-se de corpo e alma à cultura das imagens. E ela é do ponto de vista da cultura da escrita, o demônio. Os roteiristas servem a esse demônio literalmente, eles colocam as letras à disposição dele. [...] Nenhuma outra traição aos escritores, aos intelectuais, ao espírito da história é mais óbvia do que aquela cometida pelos roteiristas (1987: 152).
}

Como se pode perceber, a rejeição de Flusser à prática profissional dos roteiristas, que o leva a criticar com tanta veemência, em texto cuja primeira edição é de 1987, uma atividade que existe pelo menos desde os primórdios do cinema, decorre da sua preocupação com a expansão da cultura eletromagnética, que conferiria centralidade às imagens técnicas em detrimento dos textos escritos. Desenvolvendo argumentos que lembram o vaticínio de McLuhan sobre o fim da era de Gutemberg, assume, no entanto, posição oposta à do teórico canadense, saindo em defesa da escrita alfabética como código fundante do pensamento ocidental, que teria dado origem à consciência histórica e, consequentemente, criado as condições para a superação do mundo mágico-mítico. Por isso, reivindica, para o livro citado, o estatuto de uma petição a favor da escrita, protestando contra o risco de o alfabeto transformar-se num código auxiliar, subjugado à produção de imagens.

As ponderações de Flusser nos remetem, desse modo, para a estreita relação que se estabeleceu entre a escrita, o objeto livro e a racionalidade moderna, a partir da qual se tende a rejeitar a mobilidade de fronteiras entre os campos da produção cultural característica da cultura multimidiática. O filósofo antevê a descentralização promovida pela aceleração do processo de deslizamento dos textos do suporte impresso para os meios audiovisuais, razão pela qual acusa os roteiristas de traidores, porque estariam a serviço desse movimento. Entretanto, a própria textualidade digital abala as categorias e práticas que fundaram a ordem dos discursos e dos livros no contexto moderno, dificultando a distinção, classificação e a hierarquização dos formatos discursivos dos textos em função de sua materialidade (como livro, jornal, carta ou documento de arquivo). São abaladas também as distinções entre as mídias sonoras, visuais e textuais, cujos limites objetivos, como observou Giselle Beiguelman, são agora implodidos pela interface (2005: 13).

Diante desse quadro, sem endossar o imaginário apocalíptico que preside o ensaio mencionado de Vilém Flusser, assim como outras obras mais recentes escritas sob o signo das «profecias do fim do livro», finalizamos este artigo, acrescentando ainda mais perguntas às formuladas inicialmente. Partilhando reflexões de Roger Chartier (1992), indagamos: o que é um livro quando deixa de ser simultânea e inseparavelmente texto e objeto? Quais são as implicações, para a percepção das obras e a compreensão de seu significado, da prática de leitura de fragmentos de textos radicalmente desvinculadas da narrativa ou do argumento das quais são parte? Quais os critérios de definição de autoria quando a ideia de uma obra idêntica a si mesma é abalada pelo movimento incessante de apropriações e reciclagens? 
Tropelías. Revista de Teoría de la Literatura y Literatura Comparada, 27 (2017)

Vera Lúcia Follain de Figueiredo

\section{Bibliografia}

AQuINO, M. (2005): Eu receberia as piores notícias dos seus lindos lábios. São Paulo, Companhia das Letras.

BACK, S. (2009): «Entrevista», «Caderno Ideias», Jornal do Brasil, 24-01-2009.

BRANT, B. (2010): «Entrevista», em Terra Magazine, http://www.terramagazine.com.br/ (última consulta, 23-02-2010).

Beiguleman, G. (2005): O Livro depois do Livro. São Paulo, Peirópolis.

Bellour, R. (1997): Entre imagens: foto, cinema e vídeo. Trad. Luciana A. Penna. Campinas, São Paulo, Papirus. $1^{\text {a }}$ ed. 1990.

ChARTIER, R. (1986): «As práticas da escrita», em P. ArIÉS e G. DubY, eds., História da vida privada, 3: da Renascença ao Século das Luzes. Trad. Hildegard Feist. São Paulo, Companhia das Letras, 1991.

_ (1992): A ordem dos livros. Trad. Mary del Priori. Brasília, UNB, 1999.

Eco, U. (1985): Sobre espelhos e outros ensaios. Rio de Janeiro, Nova Fronteira, 1989.

FigueIREDO, V. (2010): Narrativas migrantes: literatura, roteiro e cinema. Rio de Janeiro, PUC/7letras.

FLuSSER, V. (1987): A escrita - há futuro para a escrita? São Paulo, Annablume, 2010.

Hollanda, C. B. (2009): Leite Derramado. São Paulo, Companhia das Letras.

HuYsSEn, A. (1996): Memórias do Modernismo. Rio de Janeiro, UFRJ.

KRAUSS, R. (1984): «A escultura no campo ampliado», Gávea: Revista semestral do Curso de Especialização em História da Arte e Arquitetura no Brasil, 1/1.

Machado, A. (2007): Arte e mídia. Rio de Janeiro, Jorge Zahar.

MACHADO, R. (2000): Foucault, a filosofia e a literatura. Rio de Janeiro, Jorge Zahar.

Mutarelli, L. (2002): O Cheiro do Ralo. São Paulo, Devir.

- (2004): Jesus Kid. São Paulo, Devir.

PATO, A. (2012): Literatura expandida: arquivo e citação na obra de Dominique Gonzalez-Foerster.

São Paulo, Edições Sesc SP - Associação Cultural Vídeo Brasil.

STIGGER, V. (2012): Delírio de Damasco. Florianópolis, Cultura e Barbárie.

(2013): Minha novela. Florianópolis, Cultura e Barbárie.

(2014): «Entrevista», Revista Garupa, em http://revistagarupa.com (última consulta, 5-122014).

WeIBEL, P. (2003): «Expanded Cinema, video and virtual environments», en J. SHAW e P. WeIBEL, eds., Future Cinema - The Cinematic imaginary after the film. MitPress, Mcambridge.

Youngblood, G. (1970): Expanded Cinema. Nova York, P. Dutton \& Co. 